\title{
TEMPORAL VARIABILITY OF RADON IN A REMEDIATED TAILING OF URANIUM ORE PROCESSING - THE CASE OF URGEIRIÇA (CENTRAL PORTUGAL)
}

S. M. Barbosa ${ }^{a}$, F. Lopes ${ }^{a}$, A. D. Correia ${ }^{b}$, S. Barbosa ${ }^{\text {b }}$, A.C. Pereira ${ }^{\text {, }}$ L.F. Neves ${ }^{c}$

a University of Lisbon, Instituto Dom Luiz, Lisboa, Portugal

${ }^{\mathrm{b}}$ EDM, Empresa de Desenvolvimento Mineiro, SA, Portugal

${ }^{c}$ IMAR, Department of Earth Sciences, University of Coimbra, Portugal

Corresponding author:

Susana M. Barbosa

sabarbosa@fc.ul.pt

University of Lisbon, Instituto Dom Luiz

Campo Grande Ed C8, 1749-016 Lisboa

Tel: +351 217500863 
3 Radon monitoring at different levels of the cover of the Urgeiriça tailings shows that the sealing is

4 effective and performing as desired in terms of containing the strongly radioactive waste resulting

5 from uranium ore processing. However, the analysis of the time series of radon concentration

6 shows a very complex temporal structure, particularly at depth, including very large and fast

7 variations from a few tens of $\mathrm{kBq} \cdot \mathrm{m}^{-3}$ to more than a million $\mathrm{kBq} \cdot \mathrm{m}^{-3}$ in less than one day. The

8 diurnal variability is strongly asymmetric, peaking at $18 \mathrm{~h} / 19 \mathrm{~h}$ and decreasing very fast around

$921 \mathrm{~h} / 22 \mathrm{~h}$. The analysis is performed for summer and for a period with no rain in order to avoid the

10 potential influence of precipitation and related environmental conditions on the radon variability.

11 Analysis of ancillary measurements of temperature, relative humidity, wind speed and wind

12 direction, as well as atmospheric pressure reanalysis data shows that the daily averaged radon

13 concentration in the taillings material is anti-correlated with the atmospheric pressure and that the

14 diurnal amplitude is associated with the magnitude of atmospheric pressure daily oscillations.

15

16 Keywords: radon; radioactive waste; meteorological effects; wavelet transform; 


\section{Introduction}

20 Uranium exploration often results in a substantial accumulation of radioactive material in the

21 natural environment. In Portugal, the uranium exploration achieved a total production of $4370 \mathrm{t}$ of $22 \mathrm{U}_{3} \mathrm{O}_{8}$ from 1913 to 2000 (Nero et al., 2004; Janssens et al., 2006). The Urgeiriça mine (central

23 Portugal) was the largest and most important uranium mine in Portugal. Until 1973 the ore was

24 mined by conventional underground mine techniques to a maximum depth of almost $500 \mathrm{~m}$,

25 afterwards in-situ leaching techniques with injection of sulphuric acid were used until 1991. The

26 Urgeiriça mine is associated with an important $\mathrm{N} 60^{\circ} \mathrm{E}$ vein containing pitchblend which cuts

27 hercynian porphyritic medium to coarse grained biotite granites. Radiometric anomalies are

28 frequent in the region, usually in association with faults and veins with strike in the range $\mathrm{N} 30^{\circ} \mathrm{E}-$

29 N60ㅌ (Pereira et al., 2010).

30 At the Urgeiriça facilities the mined ores were milled and chemically treated for uranium extraction

31 producing a large amount of radioactive waste which poses a risk to human populations (Pereira et

32 al., 2004a; Dinis and Fiúza, 2013; Pereira et al, 2014). Ambient radiation measurements at the

33 Urgeiriça mine showed that the annual ambient dose equivalent peaked at $32 \pm 11 \mathrm{mSv} / \mathrm{yr}$ at the

34 ore discharge by the milling station, while the annual ambient dose equivalent outside the mining

35 facilities was $2.4 \pm 0.1 \mathrm{mSv} / \mathrm{yr}$. Waste heaps at Urgeiriça displayed beta-gamma radiation dose

36 rates of up to $20 \mu \mathrm{Sv} / \mathrm{h}$, much above the natural radiation background (Carvalho et al, 2007).

37 Radon concentrations in soils in the surrounding area ranged from 4 to $84 \mathrm{kBq} \cdot \mathrm{m}-3$ with a median

38 value of $23 \mathrm{kBq} \cdot \mathrm{m}-3$.

39 The radioactive waste from the Urgeiriça ore processing facility was disposed over a former small

40 valley containing a streamline with occasional water flow (see Fig. 1). The tailings, occupying an

41 area of 13 ha and with an estimated volume of 1.4 million $\mathrm{m}^{3}$ are very heterogeneous particularly

42 in terms of radium $\left({ }^{226} \mathrm{Ra}\right)$ concentration which varies from 3.4 to $52 \mathrm{kBq} / \mathrm{kg}$ (Pereira et al.,

$432004 a, b)$. The depth is also very variable, ranging from a few meters to about $70 \mathrm{~m}$. The taillings

44 material is deposited directly over hercynian granites with variable degree of rock matrix alteration

45 and fracturation. Apart from a small proportion of the uranium remaining from the uranium dynamic

46 lixiviation extraction (around 10\%), the sludge deposited in the tailings contains all the other

47 radionuclides of the decay chain of this chemical element. These can be removed from the tailings

48 deposits by natural processes, thus migrating into the environment. To avoid this possible

49 contamination and associated hazards, a rehabilitation plan was concluded in 2008 by Empresa de

50 Desenvolvimento Mineiro, SA, based on an in-situ reclamation scheme for confinement of the 
51 radioactive residues (see Fig. 1). After a previous geotechnical stabilization of the pile, including

52 the construction of a peripheral concrete structure provided with surface and deep drainage 53 systems, a multi-layer cover consisting of both geological and synthetic materials was disposed

54 over the surface of the tailings (Pereira et al., 2004b; Janssens et al., 2006; EDM, 2008). The 55 effectiveness of the cover was estimated through numerical modeling by Pereira et al. (2004a) 56 based on the RESRAD code (Yu et al, 2001), pointing to a negligible dose (less than $1 \mathrm{mSv} / \mathrm{yr}$ ) to 57 the nearby population after remediation in contrast with an average effective dose of $39 \mathrm{mSv} / \mathrm{yr}$ 58 without rehabilitation.

59 In the present study, in order to evaluate the performance of the cover in confining the tailings 60 material, several radon monitoring stations were set-up at various depths corresponding to 61 different layers of the sealing. The temporal variablity of radon concentration was monitored in the 62 subsurface, both directly on the tailings materials and in the cover, as well as in the top soil near 63 the surface. The main purpose of this work is to quantify the radon concentration at the different 64 levels, in order to assess the performance of the sealing cover, and also to describe and quantify 65 the corresponding temporal changes.

\section{Material and methods}

\subsection{Radon monitoring}

Continuous radon monitoring is performed in the tailings both below and above the sealing cover.

71 The multi-layer cover is composed, from the base to the top, of a compacted clay layer with a 72 thickness of $0.60 \mathrm{~m}$, a high-density polyethylene (HPDE) layer of $2 \mathrm{~mm}$, a geotex tile membrane 73 with $10 \mathrm{~mm}$, a layer of $0.30 \mathrm{~m}$ of gravel, then $0.5 \mathrm{~m}$ of sand and finally a layer of topsoil with $0.5 \mathrm{~m}$ 74 (Fig. 2). The volumic activity of radon is measured every 15-minutes by Barasol sensors of the BMC2 type, manufactured by Algade. Radon is measured in a detection volume after filtering of the solid daughter products by a silicon solid detector (alpha detection). The energy window is set between $1.5 \mathrm{MeV}$ and $6 \mathrm{MeV}$ and the volumic activity is measured after proper calibration of the sensor (typically 50 Bq.m-3 per imp.h-1).

At the site considered in the present study the sensors are placed at three nearby boreholes $(<10$ $\mathrm{m}$ apart), corresponding to different depths: at a depth of $2.4 \mathrm{~m}$, in direct contact with the tailings material, at a depth of $1.0 \mathrm{~m}$, in the gravel above the isolation membrane, and in the topsoil at a

82 depth of about $20 \mathrm{~cm}$ from the surface. The 3" pipes are open at the bottom and covered with a 83 gas-tight lid at the top.

84 Furthermore, meteorological parameters are measured at the same site every 10-minutes 
85 including temperature, relative humidity, precipitation, wind speed and wind direction (Table 1).

86 Atmospheric pressure information is not available at the site and is taken 4 times/day from the

87 ERA-interim reanalysis (Dee et al., 2011) for the gridpoint $(40.5 \mathrm{~N}, 7.75 \mathrm{~W})$ closest to the sampling

88 site (11.9 km apart). In order to have an uniform sampling for all parameters, both the radon and

89 the meteorological data were aggregated to hourly values (local summer time). In the case of

90 surface pressure the available 4 values per day were linearly interpolated into hourly values. Only

91 the hourly time series of radon and meteorological parameters are considered hereafter. In order

92 to avoid any eventual influence of rain as well as of high groundwater levels on the radon

93 concentration and its temporal variability, time series are considered for the summer of 2011, from

9416 June to 27 July, a period of 42 days with no precipitation and no gaps in the records (Fig. 2).

\subsection{Time series of radon concentration}

Time series of radon concentration are usually non-stationary (e.g. Barbosa et al., 2007). The wavelet transform is a particularly useful tool for the analysis of non-stationary signals. The continuous wavelet transform (CWT) is often applied to geophysical signals (e.g. Torrence and Compo, 1998) providing a useful 2-dimensional description of the energy distribution for a given signal. However, the discrete wavelet transform (DWT) by formally yielding time series components rather than an image, is more amenable to the analysis of time series. In this work both the CWT and the DWT are applied. The continuous wavelet transform is computed with the R-package dpIR (Bunn, 2008) using the Morlet wavelet function. The discrete wavelet analysis is performed with the R-package waveslim (Gencay et al., 2001). Here the maximal overlap discrete wavelet transform (MODWT) is considered. The MODWT yields an additive decomposition of a time series (e.g. Percival and Mojfeld, 1997) as well as of its variance (e.g. Witcher et al., 2000 ). The MODWT is computed using a Daubechies least asymmetric (LA) wavelet filter of length 8 with reflection boundary conditions. The radon time series are decomposed into $j=4$ sub-series associated with scales from $2^{j}$ to $2^{j+1}$ hours and a smooth component corresponding so scales higher than 32 hours. The 1st two levels of the decomposition reflect high-frequency variability, the

1123 rd level reflects semi-diurnal variability (scales of 8 to 16 hours) and the diurnal variability is captured at the 4 th level of the decomposition (scales of 16 to 32 hours). The wavelet variance is obtained from the MODWT decomposition using only the wavelet coefficients not potentially

115 affected by boundary effects.

\section{Results}

118 The radon concentration values obtained at the three different depths are summarised in Fig. 3 
119 and Table 2. The results show that radon concentrations are, as expected, lowest closer to the

120 surface and highest (on the order of a million Bq. $\mathrm{m}^{-3}$ ) at the deeper point directly in contact with the

121 tailings material. Figure 3 shows the distinct distribution of the radon concentration values below

122 and above the sealing, demonstrating the efficiency of the multi-layer cover. The average (median)

123 radon concentration (middle horizontal line in Fig. 3) is $1.1 \mathrm{Mbq} \cdot \mathrm{m}^{-3}$ below the multi-layer cover, 115

$124 \mathrm{kBq} \cdot \mathrm{m}^{-3}$ within the multi-layer structure (but above the impermeable sections) and $40 \mathrm{kBq} \cdot \mathrm{m}^{-3}$ in the

125 top soil. Despite the overall higher concentration values obtained at the deeper point, the absolute

126 minimum (lower horizontal line in Fig. 3) is lowest for the deeper record (Table 2). This point is

127 further examined in section 3.1, while the temporal variability of the radon time series is addressed 128 in section 3.2 .

\subsection{Inversion events}

131 As suggested by the minimum values of radon concentration displayed in Table 2, the radon 132 concentration at the deeper point, in direct contact with the tailings material, can be lower than the 133 radon concentration above. These "inversions" occur for about $30 \%$ of the hourly observations 134 (317 values), and about half the times ( 16.5\%, 167 values) the concentration at the deepest level 135 is not only lower than at the point above, but even lower than the radon concentration at the point 136 near the surface. Inversion times are hereafter defined as the times for which the concentration at $1372.4 \mathrm{~m}$ is lower than at $1.0 \mathrm{~m}$. Figure 4 shows the time of occurrence of inversion events (the $1 \mathrm{st}$ 138 occurrence of an inversion in a sequence of inverse values) and Figure 5 the corresponding 139 duration (the number of consecutive values in a sequence of inverse values). The results show 140 that inversion events typically occur around midnight and also around 07h00, displaying a clear 141 bimodal pattern. The inversion events last usually for a few hours (mode=3 hours) but the 142 distribution is also bimodal with inversion events lasting more than 12 hours (Fig. 5). No 143 association is found between the duration and the time of occurrence of inversion events.

144 Figure 6 shows the time series of radon concentration at $2.4 \mathrm{~m}$ and $1.0 \mathrm{~m}$ depths as well as of 145 environmental parameters. Occurrences of inversion events are represented in dark, emphasizing 146 that inversions occur for both low (high) and increasing (decreasing) values of the environmental 147 variables.

\subsection{Temporal variability}

151 The temporal structure of the three time series of radon concentration is summarized in the 152 wavelet domain by the corresponding power spectrum (Fig. 7). The radon concentration below the 
cover displays a clear diurnal $(\sim 24 h)$ cycle, as well as a semi-diurnal ( $12 h)$ cycle, which is

154 however weaker (and below the 95\% confidence level) in the middle of the observation period. The radon concentration at the intermediate depth displays a diurnal cycle in the beginning of the record, but it becomes negligible afterwards. The topsoil radon concentration also exhibits some energy at the diurnal scale in the beginning of the record but it is below the $95 \%$ confidence level (low signal-to-noise ratio). The distinct energy structure of the three radon time series is confirmed by the scale-by-scale variance decomposition based on the maximal overlap discrete wavelet transform (Table 3). The diurnal range accounts for more than $50 \%$ of the variability in the radon time series below and within the cover, while for the near surface record most of the variability $(\sim 70 \%)$ is concentrated at high frequencies and periodic features are absent.

\subsubsection{Non-periodic variability}

In order to focus on non-periodic variability, the hourly values are aggregated into daily values by taking the median of all the hourly observations for a given day. Then the correlation between the daily median time series of radon concentration and the corresponding time series of environmental parameters is computed and tested for statistical significance. No correlation is found between radon variability at depth $(2.4 \mathrm{~m})$, and at the points above. The only significant correlation is for radon at 1.0 and at $0.2 \mathrm{~m}$ depths, with a correlation coefficient of 0.63 corresponding to a $95 \%$ confidence interval of [0.40;0.78]. The cross-correlation function (Fig. 8) shows that the correlation is even higher for non-zero lags, being largest when the radon concentration at $1.0 \mathrm{~m}$ depth lags 2 days behind radon concentration at $0.2 \mathrm{~m}$.

174 No correlation is found between the daily variability of the radon time series and any of the environmental variables except for radon concentration at $2.4 \mathrm{~m}$ depth and the atmospheric pressure. The correlation is small (correlation coefficient of -0.36) but statistically significant corresponding to a 95\% confidence interval of [-0.60;-0.060].

\subsubsection{Diurnal variability}

180 The diurnal cycle displayed by the subsurface radon time series $(2.4 \mathrm{~m}$ and $1.0 \mathrm{~m})$ is extracted from the 4th level of the MODWT-based multiresolution decomposition, which is associated with scales

182 from $16 \mathrm{~h}$ to $32 \mathrm{~h}$. Exactly the same procedure is used to extract the diurnal cycle of the available 183 environmental parameters. The resulting diurnal cycle is then characterized in terms of amplitude 184 (max-min for each day) and phase (time of max/min for each day), and the correlation between the daily amplitudes of radon and of environmental diurnal cycles is examined.

186 The diurnal amplitude of the radon concentration at the deeper point $(2.4 \mathrm{~m})$ shows a moderate 
correlation with the daily amplitude of temperature. The value of the correlation coefficient is 0.57 corresponding to a $95 \%$ confidence interval of $[0.33 ; 0.75]$. However, the association between temperature and radon concentration doesn't seem to be causal, since the cross-correlation function suggests that temperature follows radon concentration instead of the opposite. A smaller but significant correlation is also found with the atmospheric pressure daily amplitude. The value of the correlation coefficient is 0.39 corresponding to a 95\% confidence interval of [0.092;0.62].

For the radon concentration at intermediate depth $(1.0 \mathrm{~m})$ no correlation is found with the diurnal amplitude of meteorological variables.

The phase of the diurnal cycle of the subsurface radon records is described in terms of the time of the $\mathrm{max} / \mathrm{min}$ for each day (Fig. 9). At the deeper site the maximum (minimum) occurs at $18 \mathrm{~h}(06 \mathrm{~h}$ ) while at the intermediate depth the maximum (minimum) occurs at $16 \mathrm{~h}(04 \mathrm{~h})$. There is however some variability from day to day. Despite the much more flexible description of diurnal variability provided by the MODWT (e.g. in comparison to a Fourier analysis), the resulting components still retain some shape induced by the wavelet function itself and above all reflect an averaged behavior of the diurnal cycle, being unable to accurately describe its shape, particularly the very sharp and asymmetric features. Figure 10 illustrates the variety of shapes of the diurnal cycle of radon concentration at $2.4 \mathrm{~m}$ depth. During the 42 days dry period considered in the present study, the diurnal cycle displays for more than $50 \%$ of the days a strongly asymmetric peak at about $18 / 19$ hours. Of these about $31 \%$ display an additional secondary peak at $5 / 6$ hours. The diurnal cycle exhibits a single symmetric peak for about $20 \%$ of the days, either a sharp peak at $18 \mathrm{~h} \mathrm{(12 \%}$ of cases) or a single peak at 5/6h leveling off after $\sim 3 \mathrm{pm}$ ( $9 \%$ of cases). Other shapes are obtained for about $25 \%$ of the days. The asymmetric peak observed in $\sim 52 \%$ of the days is characterized by a slow ( $~ 8 \mathrm{~h})$ increase in radon concentration to the peak value followed by a much faster decrease (typically $\sim 3 \mathrm{~h}$ ) in the descending part of the cycle. The asymmetric behavior of the diurnal cycle is further examined by computing, for each individual day, the 1st derivative of the radon concentration values. The times for which the radon variation is more abrupt are obtained from the largest value of the derivative and occur at $21 \mathrm{~h}-22 \mathrm{~h}$, corresponding typically to a drop in radon concentration of more than $65 \%$ in just 1 hour.

\section{Discussion}

The analysed time series of radon concentration display very different average levels reflecting the distinctive materials in which the radon gas is generated: topsoil at $0.2 \mathrm{~m}$ depth, gravel at $1 \mathrm{~m}$ depth and taillings material at $2.4 \mathrm{~m}$ depth. Beyond mean concentrations the time series also display very distinct temporal patterns. Radon concentration in the taillings material is characterised by very 
221 large daily fluctuations, while in the topsoil daily cycles are absent but radon concentration exhibits 222 non-periodic variations. The time series at the middle level in the gravel material displays an 223 intermediate behavior with both daily periodic and non-periodic variability.

224 The time series of radon concentration above the geotextile cover display a similar long-term 225 temporal pattern characterised by a broad peak around 27/06/2011 and comparatively stable 226 levels in between, the mean level being higher at the beginning of the record than at the end. The 227 correlation between the daily averaged values of the two time series is highest for a time lag of 2 228 days suggesting that non-periodic variability in radon concentration at $1 \mathrm{~m}$ depth is driven by 229 surface variability.

230 The daily variability of radon concentration at the middle level is stronger in the beginning of the 231 record (from 15/06/2011 to about 06/07/2011). Likewise while a consistent periodic daily cycle is 232 not detectable at the shallower depth, variability at the daily scale is higher in the same period at 233 the beginning of the record which coincides with overall higher mean radon concentrations. This 234 dependence of the amplitude of variations on the mean radon level is consistent with the 235 heteroskedastic behavior of radon time series resulting from the Poisson nature of radon 236 measurements and consequent coupling between mean and variance (Barbosa et al, 2007; Szabo 237 et al, 2013).

238 The temporal variability of radon concentration at $2.4 \mathrm{~m}$ depth, in the taillings material, is dominated 239 by very high daily oscillations. While only a subset of the data, corresponding to dry conditions, is 240 considered in the present study, this is a longstanding feature as can be seen in Fig. 12. Again, 241 because of the intrinsic coupling between mean and variance in radon time series, very large mean 242 concentration values (resulting from the source of the radon gas, the heavily contaminated uranium 243 tallings material) are associated with corresponding very large temporal variations.

244 Notwithstanding the very large radon concentrations in the taillings material, some of the values 245 are lower than the concurrent concentrations at the intermediate level. Although these designated 246 inversion events correspond only to $31 \%$ of the hourly values at $2.4 \mathrm{~m}$ depth, they are frequent 247 occurring every day except for 7 out of the total 42 days: 16/06, 17/06, 02/07, 11/07, 17/07, 21/07 248 and 26/07. These specific days with no inversion events correspond to plateaus in radon 249 concentration (see Fig. 3a) and coincide with minima in atmospheric pressure, in particular 250 pressure minima resulting from a large decrease in pressure associated with weather fronts lasting 251 for 1.5-2 days. Changes in atmospheric pressure of the order of a few percent occurring over a 252 period of 1-2 days and associated with the passage of frontal systems can result in 20 to $60 \%$ 253 changes in the radon flux (Clements \& Wilkening, 1974). During summer a pressure decrease of $2541 \%$ can cause a $50 \%$ increase in radon concentration (Woith, 1996). 
255 The daily averaged radon concentration below the geotextile cover is anti-correlated with

256 atmospheric pressure. Barometric pumping is known to significantly influence soil gas radon 257 concentration (e.g Clements \& Wilkening, 1974; Ball et al, 1991; Chen et al, 1995; Pinault \& 258 Baubron, 1996; Wyatt et al, 1995; Zafrir et al, 2013). Radon-rich air flows into the atmosphere 259 during atmospheric pressure drops while during rising air pressure the radon concentration is 260 dilluted by the entry of radon-free atmospheric air into the soil pore space displacing the radon-rich 261 soil air to larger depths (Van der Spoel et al., 1998; Perrier et al., 2004; Perrier \& Richon, 2010).

262 The daily amplitude of radon concentration is correlated with the daily amplitude of atmospheric 263 pressure indicating that the intensity of the diurnal cycle in radon concentration is associated with 264 the magnitude of daily pressure oscillations. The bi-modal character of the diurnal cycle of radon 265 concentration, while not the rule (corresponds to $31 \%$ of days) also points to some influence of 266 atmospheric pressure on radon diurnal variability. In this case of a multi-layer vertical structure of material with very distinct characteristics the response of radon to atmospheric pressure is expected to be complex since the barometric response of radon is highly influenced by the transport properties of the media (Perrier \& Girault, 2013).

\section{Conclusions}

272 Radon concentration measured at different levels of the cover of the Urgeiriça tailings is 273 characterized by very different average values below, inside and above the multi-layer cover, 274 showing that the sealing structure is performing as expected and effectively reducing surface 275 radioactivity levels.

276 Furthermore, the obtained time series of radon concentration display a very rich temporal structure which has been examined here in detail. The time series closer to the surface is dominated by high-frequency variability and doesn't show periodic features. The time series at the intermediate depth displays a diurnal cycle with maximum (minimum) at $16 \mathrm{~h}(04 \mathrm{~h})$ and is correlated with the radon concentration near the surface with a time lag of 2 days suggesting an influence of surface conditions on the underneath radon variability. The time series at the largest depth, in direct contact with the radioactive waste material, displays the most complex and volatile temporal structure, including very large and fast variations from a few tens of kBq. $\mathrm{m}^{-3}$ to more than a million $\mathrm{kBq} \cdot \mathrm{m}^{-3}$ in less than one day. The diurnal variability is typically characterized by a strongly asymmetric peak with maximum at $18 \mathrm{~h} / 19 \mathrm{~h}$, decreasing very fast around $21 \mathrm{~h} / 22 \mathrm{~h}$, and a secondary peak at $5 \mathrm{~h} / 6 \mathrm{~h}$.

287 The radon concentration at the deeper level is correlated with atmospheric pressure both in terms 288 of non-periodic and periodic variability. The daily averaged concentration is anti-correlated with 
289 atmospheric pressure and the amplitude of daily oscillations is correlated with the magnitude of 290 daily pressure oscillations. The daily amplitude of the diurnal cycle seems to be associated with the 291 daily amplitude of air temperature but in a non-causal way.

292 Despite the very distinct average values of radon concentration above and below the cover, the 293 radon concentration at the higher depth often displays concentration values below the ones 294 registered at the intermediate depth, typically occurring around midnight and also in the morning 295 ( 7h) and lasting for a few hours ( 3h), sometimes longer (> 10h). These inversion events seem 296 to be unrelated with environmental conditions other than atmospheric pressure, since they occur 297 for both low (high) and increasing (decreasing) values of the corresponding environmental 298 parameters. Periods of atmospheric pressure drops related to weather fronts are associated with 299 plateaus in radon concentration and absence of inversion events.

300 The 42-days dry period in the summer considered here was selected in order to avoid potential 301 influences of rainfall and high groundwater levels on the results. Investigation of the potential 302 influence of other meteorological parameters including relative humidity, temperature and wind 303 showed no association between the observed radon concentrations and the environmental 304 conditions. Despite the fact that a connection between atmospheric pressure and radon variability 305 was found in the present study, the results are constrained by the low sampling rate (4 times/day) 306 of the available reanalysis data, which considerably limits the sub-hourly variability features. In 307 addition to high-resolution pressure information, additional work on the origin of the observed 308 temporal patterns would probably require groundwater and soil moisture information in order to 309 address the possible physical mechanisms explaining the features described here, which deserve 310 further investigation.

\section{Acknowledgments}

313 This work was done in the framework of the project PTDC/CTE-GIX/110325/2009, funded by FCT. 314 


\section{References}

Ball, T. K., Cameron, D. G., Colma, T. B., Roberts, P. D., 1991. Behavior of radon in the geological environment: a review. Q. J. Eng. Geol. 24, 169-182.

Barbosa, S.M., Steinitz, G.,Piatibratova, O., Silva, M.E., Lago, P., 2007. Radon variability at the Elat granite, Israel: Heteroscedasticity and nonlinearity. Geophys. Res. Lett. 34, L15309, doi: 10.1029/2007GL030065

Carvalho, F. P., Madruga, M.J., Reis, M.C., Alves, J.G., Oliveira, J.M., Gouveia, J., Silva, L., 2007. Radioactivity in the environment around past radium and uranium mining sites of Portugal. J. Environ. Radioactiv. 96, 39-46.

Chen, C., Thomas, D. M., Green, R. E., 1995. Modeling of radon transport in unsaturated soil. J. Geophys. Res. 100, 15517-15525.

Clements, W. E., Wilkening, M. H., 1974. Atmospheric presssure effects on Rn-222 transport accross the earth-air interface. J. Geophys. Res. 79, 5025--5029\}

Dee, D.P., Uppala, S. M., Simmons, A.J., Berrisford, P., Poli, P., Kobayashi, S., Andrae, U., Balmaseda, M.A., Balsamo, G., Bauer, P., Bechtold, P., Beljaars, A.C.M., van de Berg, L., Bidlot, J., Bormann, N., Delsol, C., Dragani, R., Fuentes, M., Geer, A.J., Haimberger, L., Healy, S.B., Hersbach, H., Hólm, E V., Isaksen, L., Kållberg, P., Köhler, M., Matricardi, M., McNally, A.P., Monge-Sanz, B.M., Morcrette, J.-J., Park, B.-K., Peubey, C., de Rosnay, P., Tavolato, C., Thépaut, J.-N., Vitart, F., 2011. The era-interim reanalysis: configuration and performance of the data assimilation system. Q. J. Roy. Meteor. Soc. 137, 553-597.

Dinis, M.L., Fiúza, A., 2013. Occupational exposure during remediation works at a uranium tailings pile. J. Environ. Radioactiv. 119, 63-69.

EDM, 2008. Empresa de Desenvolvimentos Mineiro, Brochura da Inauguração daBarragem Velha da Urgeiriça. http://www.edm.pt/images/folheto_urgeirica.pdf.

Fisher, N.I., 1993. Statistical analysis of circular data. Cambridge University Press, Cambridge.

Gencay, R., Selcuk, F., Whitcher, B., 2001. An Introduction to Wavelets and Other Filtering Methods in Finance and Economics, Academic Press, San Diego.

Janssens, A., Ordax, B.A., Van der Strich, S., Vallet, P., 2006. Technical Report: Verification under the terms of article 35 of the Euratom Treaty. Technical Report PT-06/7. European Commission.

Nero, J.M.G., Dias, J.M.M., Pereira, A.J.S.C., Neves, L.J.P.F., Torrinha, J., 2005. Environmental evaluation and remediation methodologies of radioactive abandoned mines in Portugal. Proceedings of the International Workshop on Environmental Contamination from Uranium Production Facilities and Remediation Measures, International Atomic Energy Agency, p. 145-158. 
Percival, D., Walden, A.T., 2000. Wavelet methods for time series analysis. Cambridge University Press, Cambridge.

Percival, D.B., 2008. Analysis of Geophysical Time Series using Discrete Wavelet Transforms: An Overview. In: Lecture Notes in Earth Sciences 112, 61-79, Springer Berlin / Heidelberg

Percival, D., Mojfeld, H., 1997. Analysis of subtidal coastal sea level fluctuations using wavelets. J. Am. Stat. Assoc. 92, 868-880.

Pereira, R., Barbosa, S., Carvalho, F.P., 2014. Uranium mining in Portugal: a review of the environmental legacies of the largest mines and environmental and human health impacts. Environmental Geochemistry and Health 36, 285-301.

Pereira, A.J.S.C., Godinho, M.M., Neves, L.J.P.F., 2010. On the influence of faulting on small scale soilgas radon variability - a case study in the Iberian uranium province. J. Environ. Radioactiv. 101, 875-882.

Pereira, A.J.S.C., Dias, J.M.M., Neves, L.J.P.F. e Nero, J.M.G., 2004a. Modelling of the long term efficiency of a rehabilitation plan for a uranium mill tailings deposit (Urgeiriça, Central Portugal). In: Proceedings do 11th International Congress of the International Radiation Protection Association, 10p.

Pereira, A.J.S.C., Neves, L.J.P.F., Dias, J.M.M., Campos, A.B.A., Barbosa, S.V.T., 2004b. Evaluation of the radiological hazards from uranium mining and milling wastes (Urgeiriça e Central Portugal). In: Proceedings do 11th International Congress of the International Radiation Protection Association, 10p.

Perrier, F., Richon, P., Crouzeix, C., Morat, P. Le Mouël, J.-L., 2004. Radon-222 signatures of natural ventilation regimes in an underground quarry. J. Environ. Radioactiv.71, 17-32.

Perrier, F., Richon, P., 2010. Spatiotemporal variation of radon and carbon dioxide concentrations in an underground quarry: coupled processes of natural ventilation, barometric pumping and internal mixing. J. Environ. Radioactiv. 101, 279-296.

Perrier, F., Girault, F., 2013. Harmonic response of soil radon-222 flux and concentration induced by barometric oscillations. Geophys. J. Int. 195, 945-971.

Pinault, J., Baubron, J., 1996. Signal processing of soil gas radon, atmospheric pressure, moisture, and soil temperature data: A new approach for radon concentration modeling. J. Geophys. Res. 101, 3157-3171.

Szabó, A.Z., Jordan, G., Horváth, Á., Szabó, C., 2013. Dynamics of soil gas radon concentration in a highly permeable soil based on a long-term high temporal resolution observation series. J. Environ. 378 Radioactiv. 124, 74-83.

379 Torrence, C., Compo, G. P., 1998. A practical guide to wavelet analysis. B. Am. Meteorol. Soc. 79, 61380 78. 
382 transport of radon in a homogeneous column of dry sand. Health Phys. 74, 48-63.

383 Whitcher, B., Guttorp, P., Percival, D.B., 2000. Wavelet analysis of covariance with application to 384 atmospheric time series. J .Geophys. Res. 105, 14,941-14,962.

385 Woith, A., 1996. Spatial and temporal variations of radon in ground air and ground water within the 386 Mudurnu Valley, NW-Turkey. A contribution to the Turkish-German Joint Project on Earthquake Research, 387 PhD thesis, 142 pp, Christian-Albrechts-University, Kiel.

388 Wyatt, D.E. Richers, D.M., Pirkle, R.J., 1995. Barometric pumping effects on soil gas studies for 389 geological and environmental characterization. Environ. Geol. 25, 243-250.

390 Yu, C., Zielen A.J., Cheng J. J., 2001. User's Manual for RESRAD, version 6. ANL/EAD-4. Argonne 391 National Laboratory, Argonne, USA.

392 Zafrir, H., Barbosa, S. M., Malik, U., 2013. Differentiation between the effect of temperature and 393 pressure on radon within the subsurface geological media. Radiat. Meas. 49, 39-56. 


\section{FIGURE CAPTIONS}

Figure 1: Geographical location \& geological setting of the Urgeiriça taillings.

Figure 2: Measurement set-up.

Figure 3: Hourly time series of radon concentration measured at (a) $2.4 \mathrm{~m}$, (b) $1.0 \mathrm{~m}$ and (c) $0.2 \mathrm{~m}$ depths during 16 June to 27 July 2011 .

Figure 4: Boxplots of the radon concentration values (a) measured at the 3 depths and (b) detailed view for the shallower measurements.

Figure 5: Rose histogram for the occurrence time of inversion events (radon concentration at $2.4 \mathrm{~m}<$ concentration at $1.0 \mathrm{~m}$ depth). The black point depicts the average time of occurrence of inversion events.

Figure 6: Histogram of the duration (in hours) of inversion events (radon concentration at $2.4 \mathrm{~m}<$ concentration at $1.0 \mathrm{~m}$ depth).

Figure 7: Time series (grey) of radon concentration (a) at $2.4 \mathrm{~m}$ and (b) $1.0 \mathrm{~m}$ depths and of environmental parameters (c) temperature, (d) pressure, (e) wind speed, (f) wind direction and (g) relative humidity. Black points denote inversion occurrences (times for which radon concentration at $2.4 \mathrm{~m}<$ concentration at $1.0 \mathrm{~m})$.

Figure 8: Continuous wavelet transform (CWT) based on the Morlet function for the radon time series (a) at $2.4 \mathrm{~m},(\mathrm{~b}) 1.0 \mathrm{~m}$ and (c) $0.2 \mathrm{~m}$ depths. The black contour indicates statistically significant regions ( $95 \%$ confidence level).

Figure 9: 9: Cross-correlation function (CCF) for radon time series at $1.0 \mathrm{~m}$ and $0.2 \mathrm{~m}$ depths (positive lags correspond to radon at $1.0 \mathrm{~m}$ following radon at $0.2 \mathrm{~m}$ ). The 
horizontal dashed lines represent the $95 \%$ confidence interval for white noise.

Figure 10: Phase of the diurnal cycle of radon concentration: time of (a) maximum at $2.4 \mathrm{~m}$, (b) maximum at $1.0 \mathrm{~m}$, (c) minimum at $2.4 \mathrm{~m}$ and (d) minimum at $1.0 \mathrm{~m}$ depths. The solid circle represents the (circular) average value.

Figure 11: Time series of radon concentration at $2.4 \mathrm{~m}$ for selected individual days, (a) 15/06, (b) 17/06, (c) 20/06, (d) 09/07, (e) 17/07 and (f) 21/07

Figure 12: Hourly time series of radon concentration measured at $2.4 \mathrm{~m}$ for the whole year 2011. Gaps in May and August-September 2011 are due to instrumental issues. 


\section{FIGURES}

Figure 1: Geographical location \& geological setting of the Urgeiriça taillings.

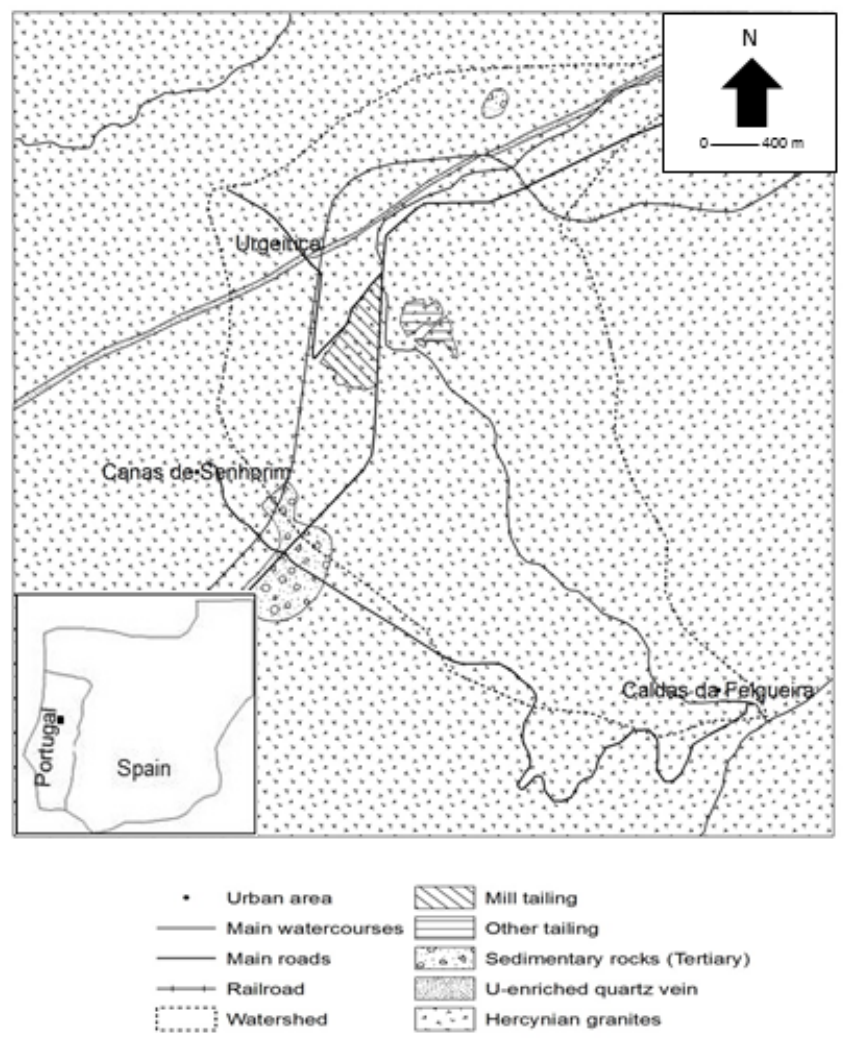


Figure 2: Measurement set-up.

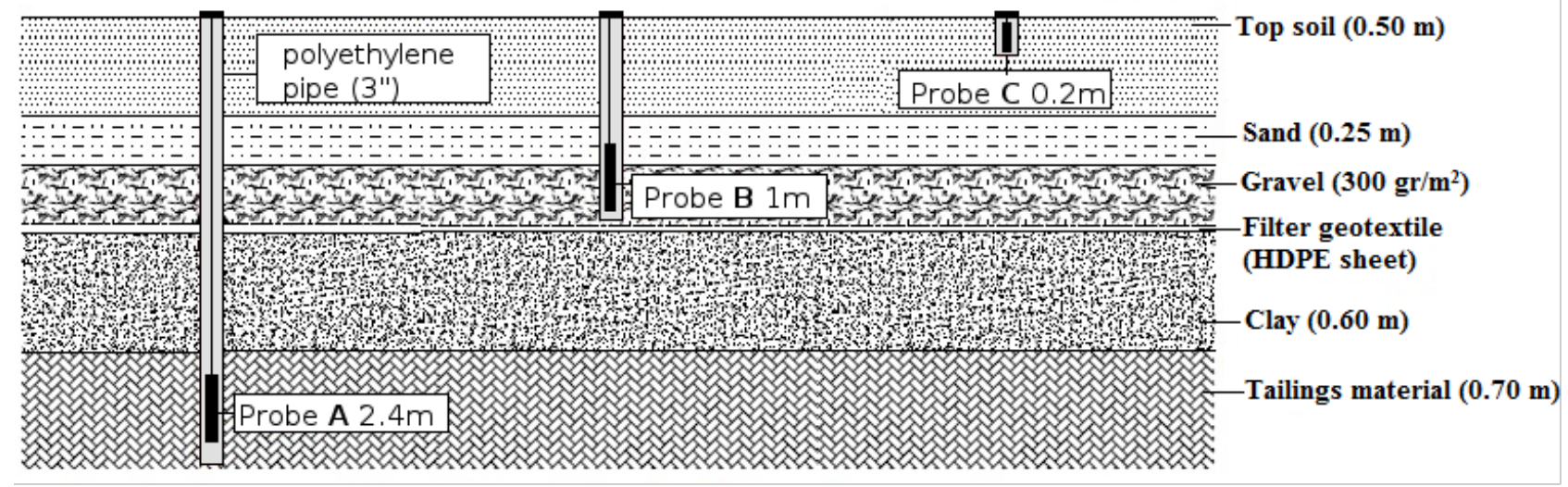


Figure 3: Hourly time series of radon concentration measured at (a) $2.4 \mathrm{~m}$, (b) $1.0 \mathrm{~m}$ and (c) $0.2 \mathrm{~m}$ depths during 16 June to 27 July 2011 .
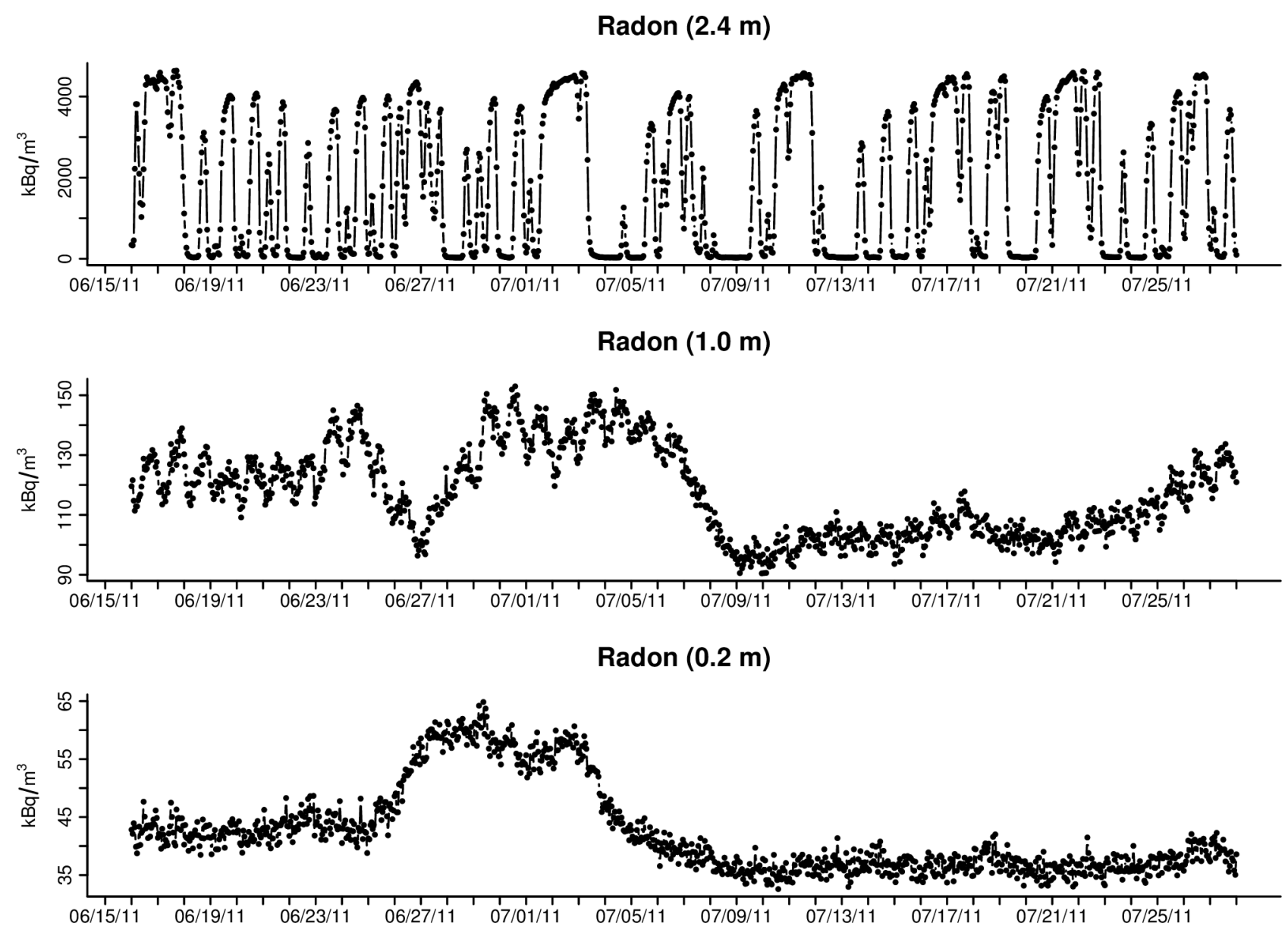
Figure 4: Boxplots of the radon concentration values (a) measured at the 3 depths and (b) detailed view for the shallower measurements.
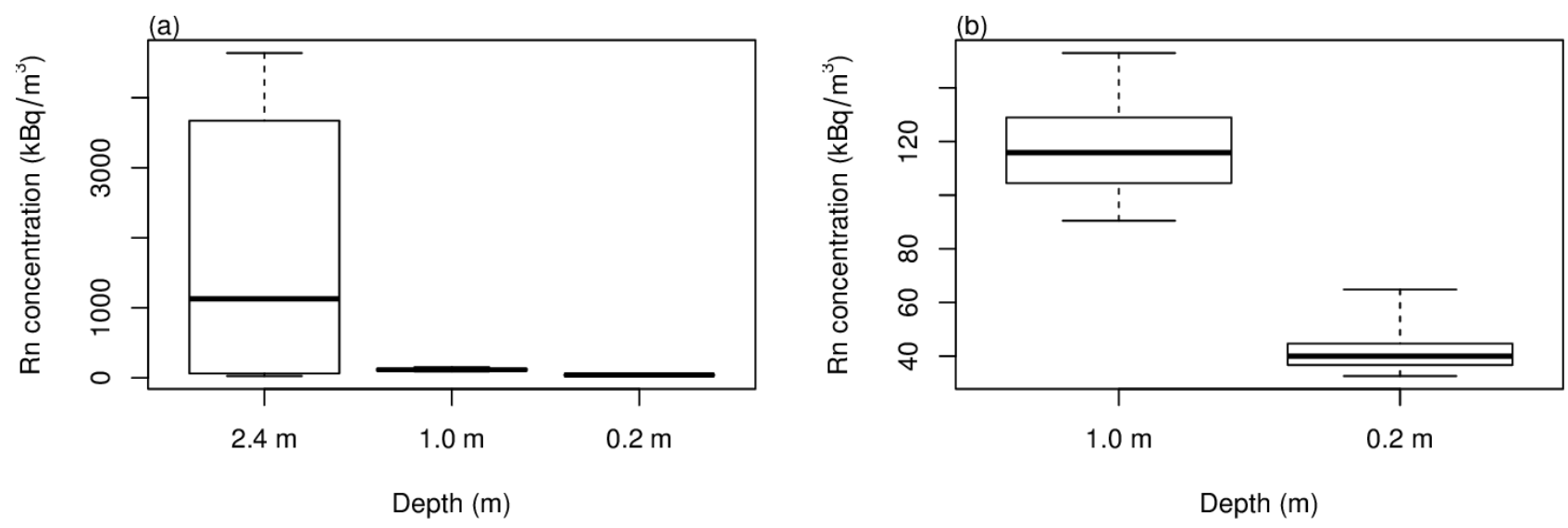
Figure 5: Rose histogram for the occurrence time of inversion events (radon concentration at $2.4 \mathrm{~m}<$ concentration at $1.0 \mathrm{~m}$ depth). The black point depicts the average time of occurrence of inversion events.

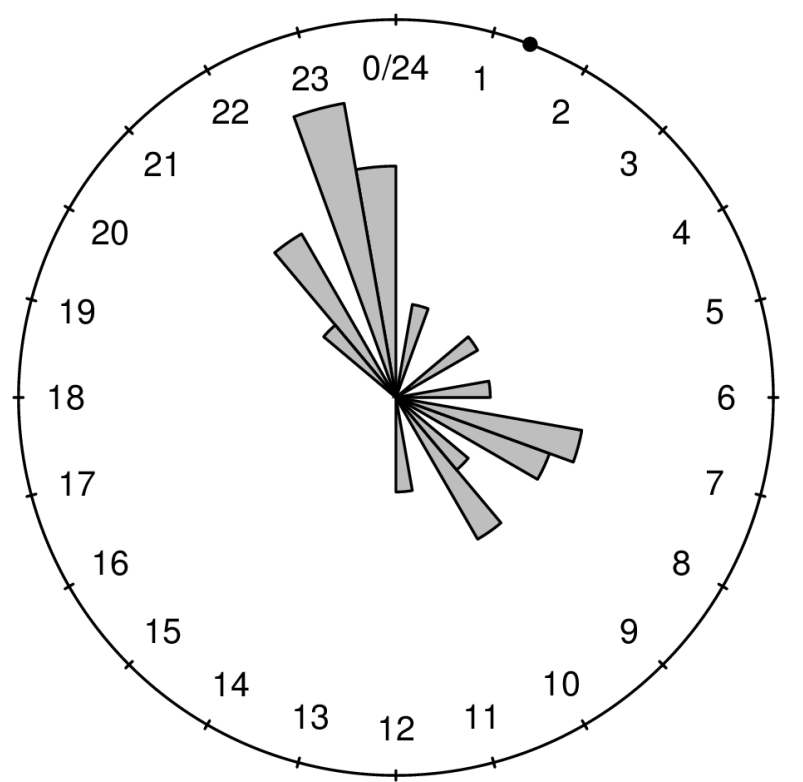


Figure 6: Histogram of the duration (in hours) of inversion events (radon concentration at $2.4 \mathrm{~m}<$ concentration at $1.0 \mathrm{~m}$ depth).

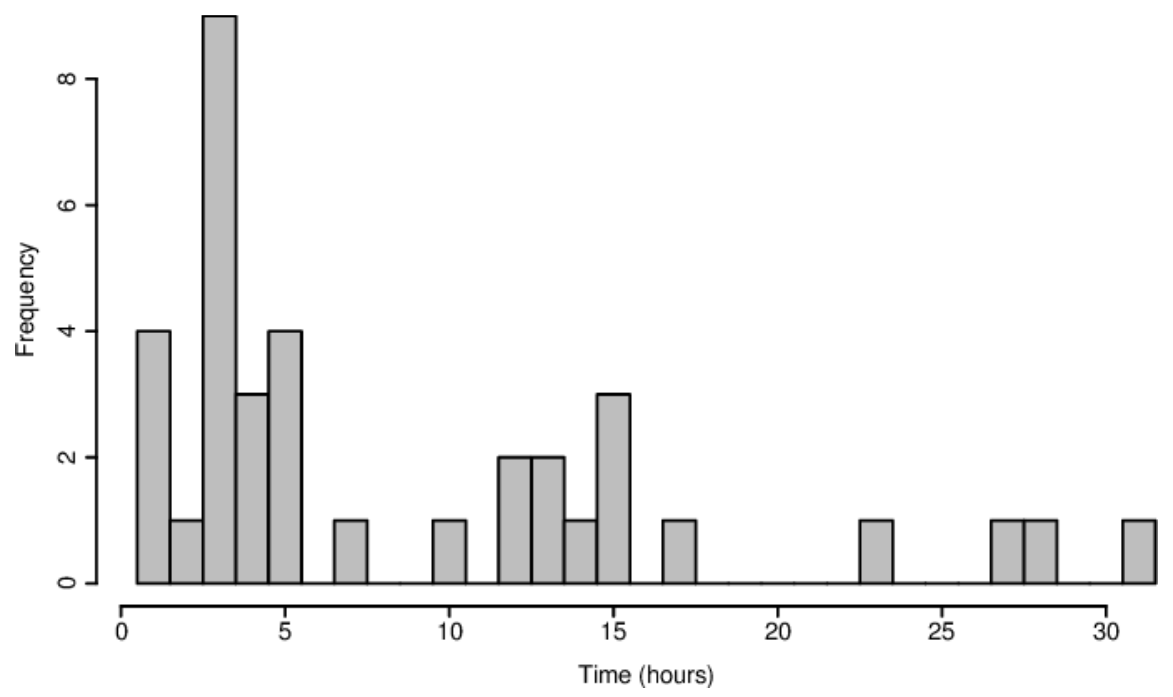


Figure 7: Time series (grey) of radon concentration (a) at $2.4 \mathrm{~m}$ and (b) $1.0 \mathrm{~m}$ depths and of environmental parameters (c) temperature, (d) pressure, (e) wind speed, (f) wind direction and $(\mathrm{g})$ relative humidity. Black points denote inversion occurrences (times for which radon concentration at $2.4 \mathrm{~m}<$ concentration at $1.0 \mathrm{~m}$ ).
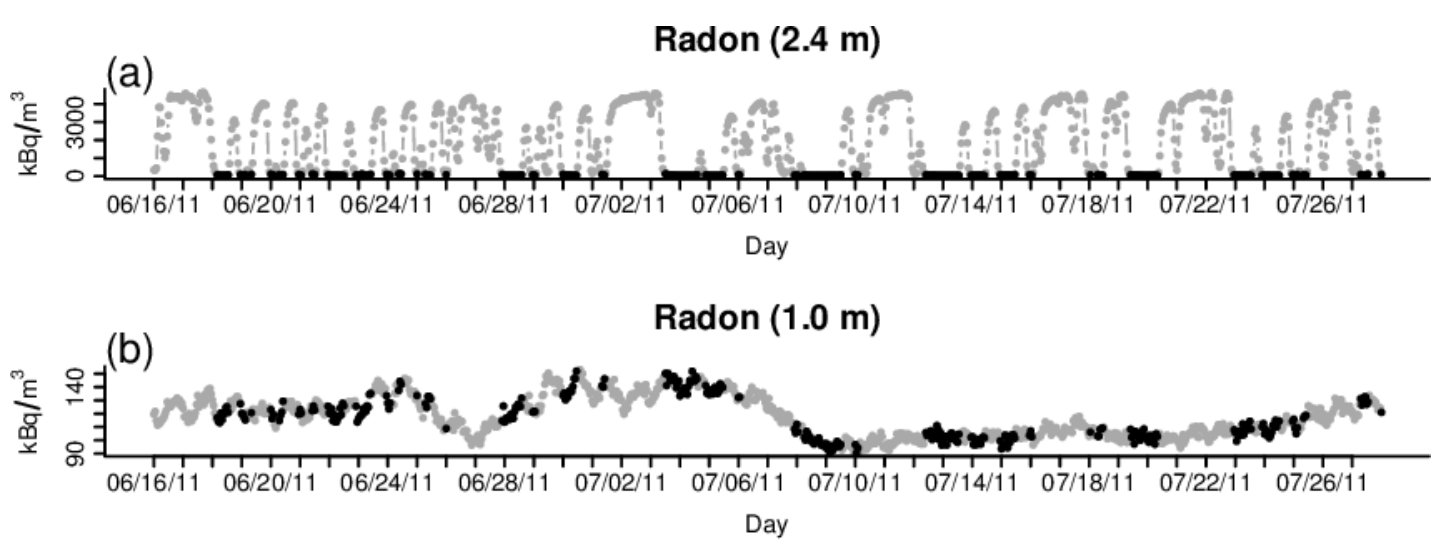

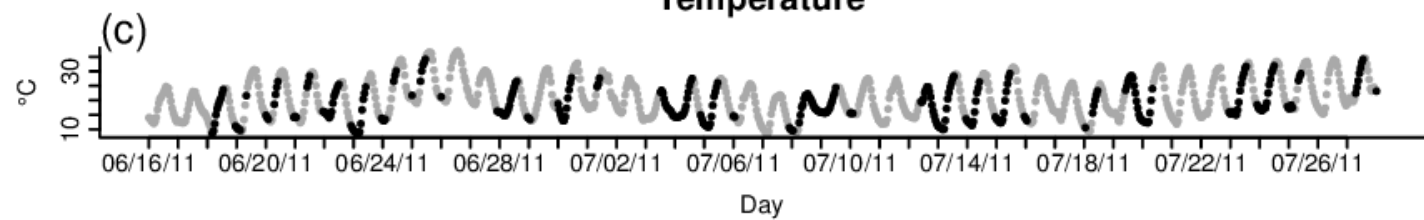

Temperature

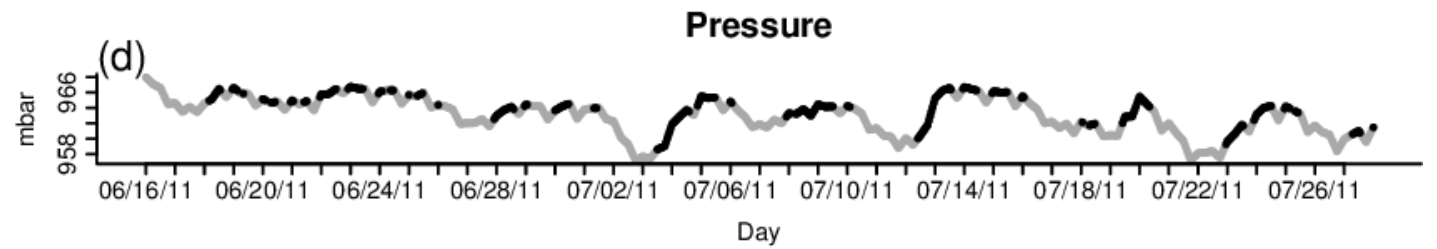

Wind speed

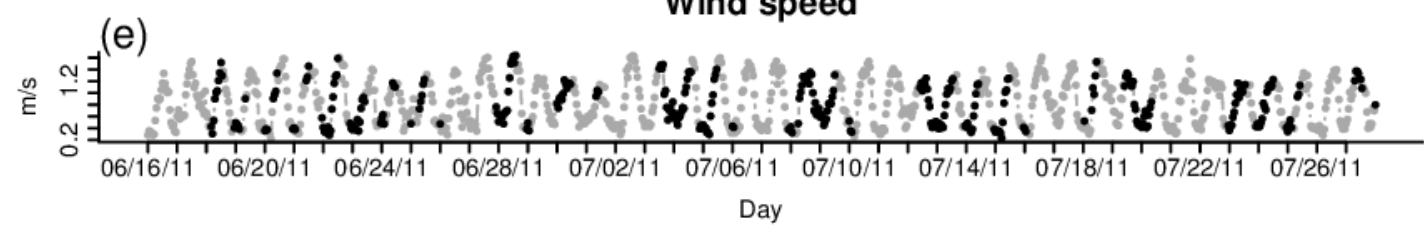

Wind direction

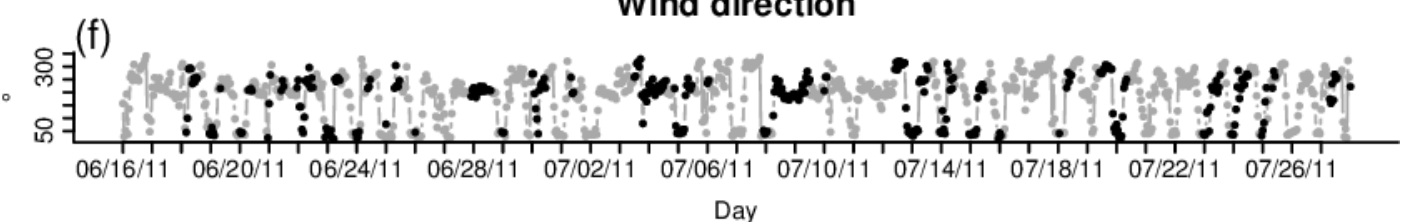

Relative humidity

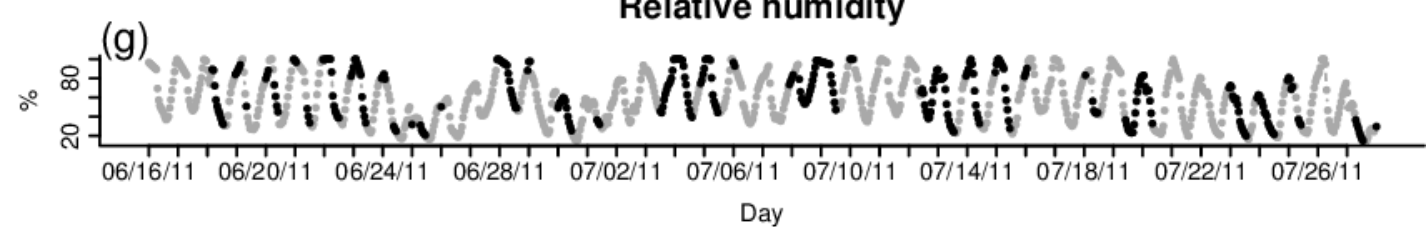


Figure 8: Continuous wavelet transform (CWT) based on the Morlet function for the radon time series (a) at $2.4 \mathrm{~m},(\mathrm{~b}) 1.0 \mathrm{~m}$ and (c) $0.2 \mathrm{~m}$ depths. The black contour indicates statistically significant regions ( $95 \%$ confidence level).

(a)

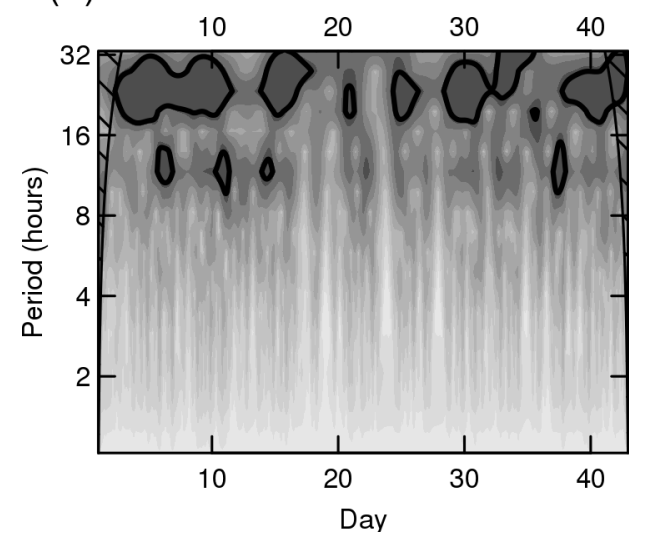

(b)

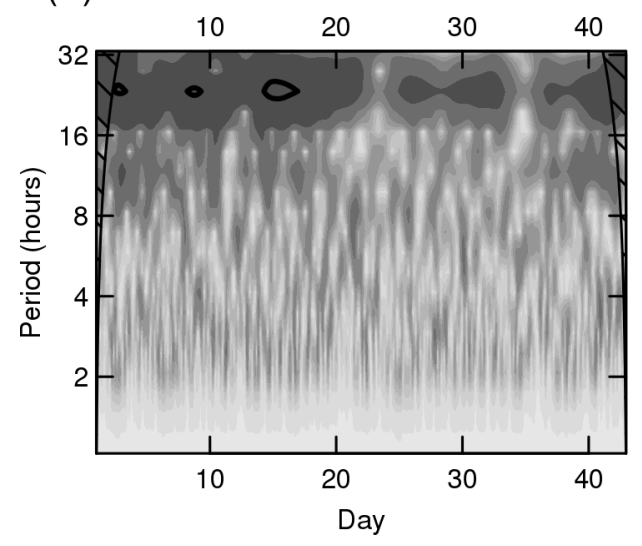

(c)

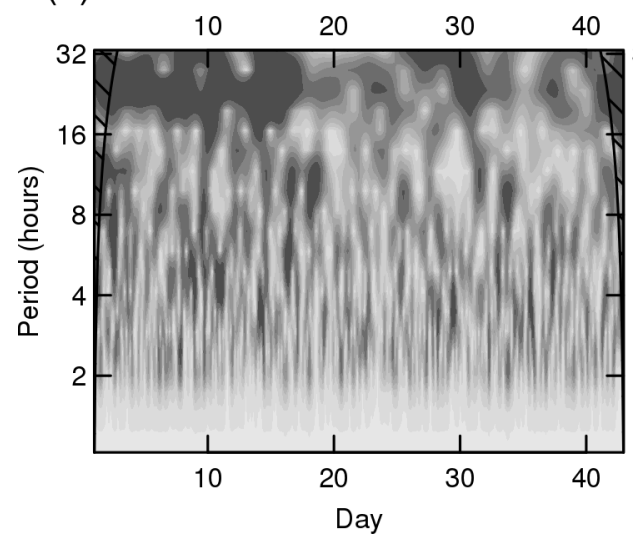


Figure 9: Cross-correlation function (CCF) for radon time series at $1.0 \mathrm{~m}$ and $0.2 \mathrm{~m}$ depths (positive lags correspond to radon at $1.0 \mathrm{~m}$ following radon at $0.2 \mathrm{~m}$ ). The horizontal dashed lines represent the $95 \%$ confidence interval for white noise.

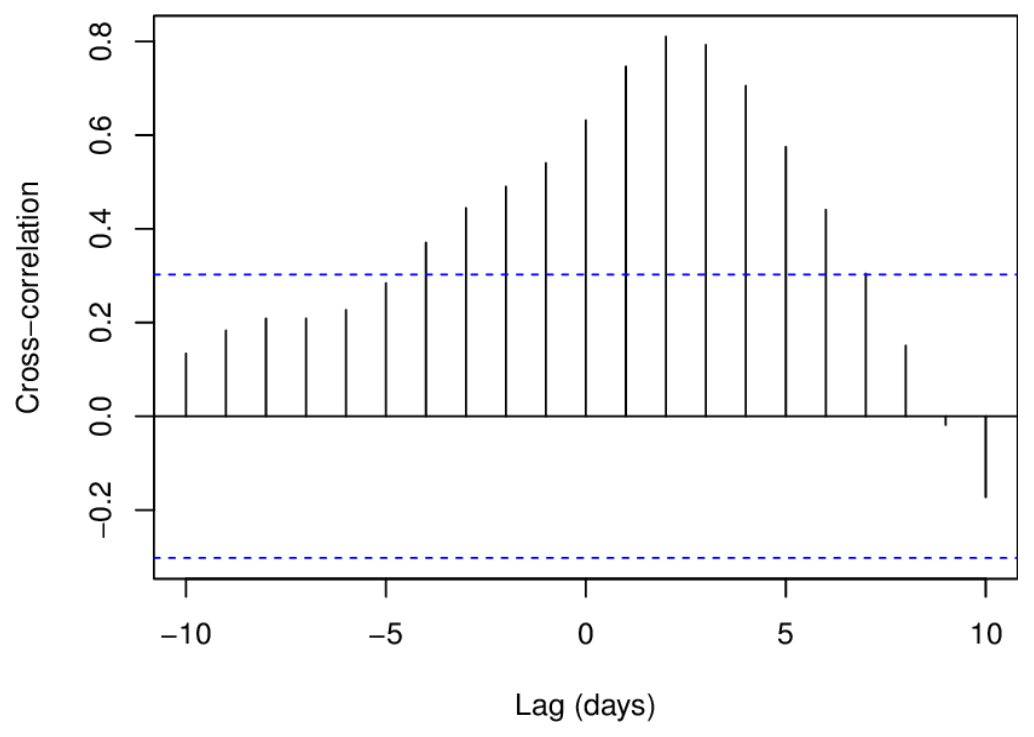


Figure 10: Phase of the diurnal cycle of radon concentration: time of (a) maximum at $2.4 \mathrm{~m}$, (b) maximum at $1.0 \mathrm{~m},(\mathrm{c})$ minimum at $2.4 \mathrm{~m}$ and (d) minimum at $1.0 \mathrm{~m}$ depths. The solid circle represents the (circular) average value.

(a)

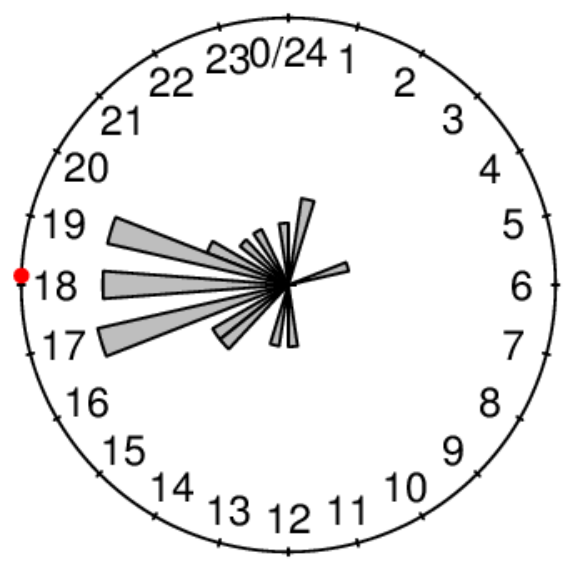

(c)

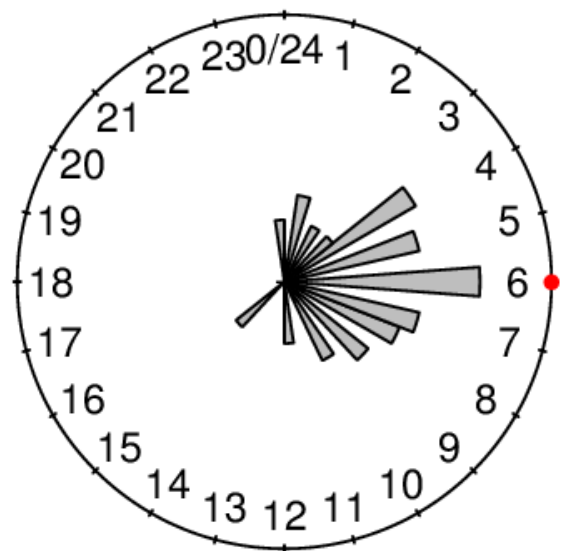

(b) $\max \operatorname{Rn}(1 \mathrm{~m})$

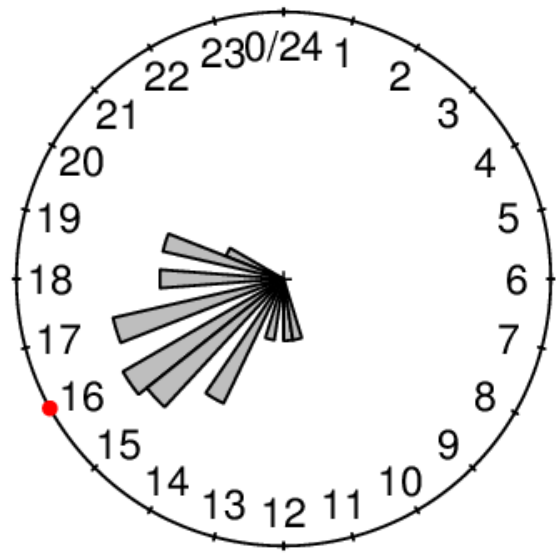

(d) mon Rn (1m)

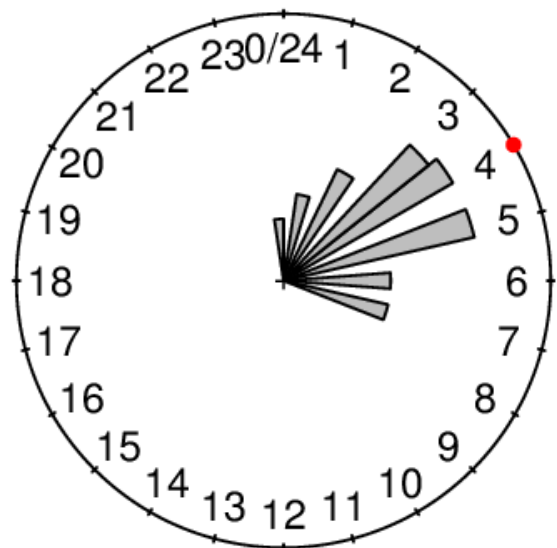


Figure 11: Time series of radon concentration at $2.4 \mathrm{~m}$ for selected individual days, (a) 15/06, (b) 17/06, (c) 20/06, (d) 09/07, (e) 17/07 and (f) 21/07
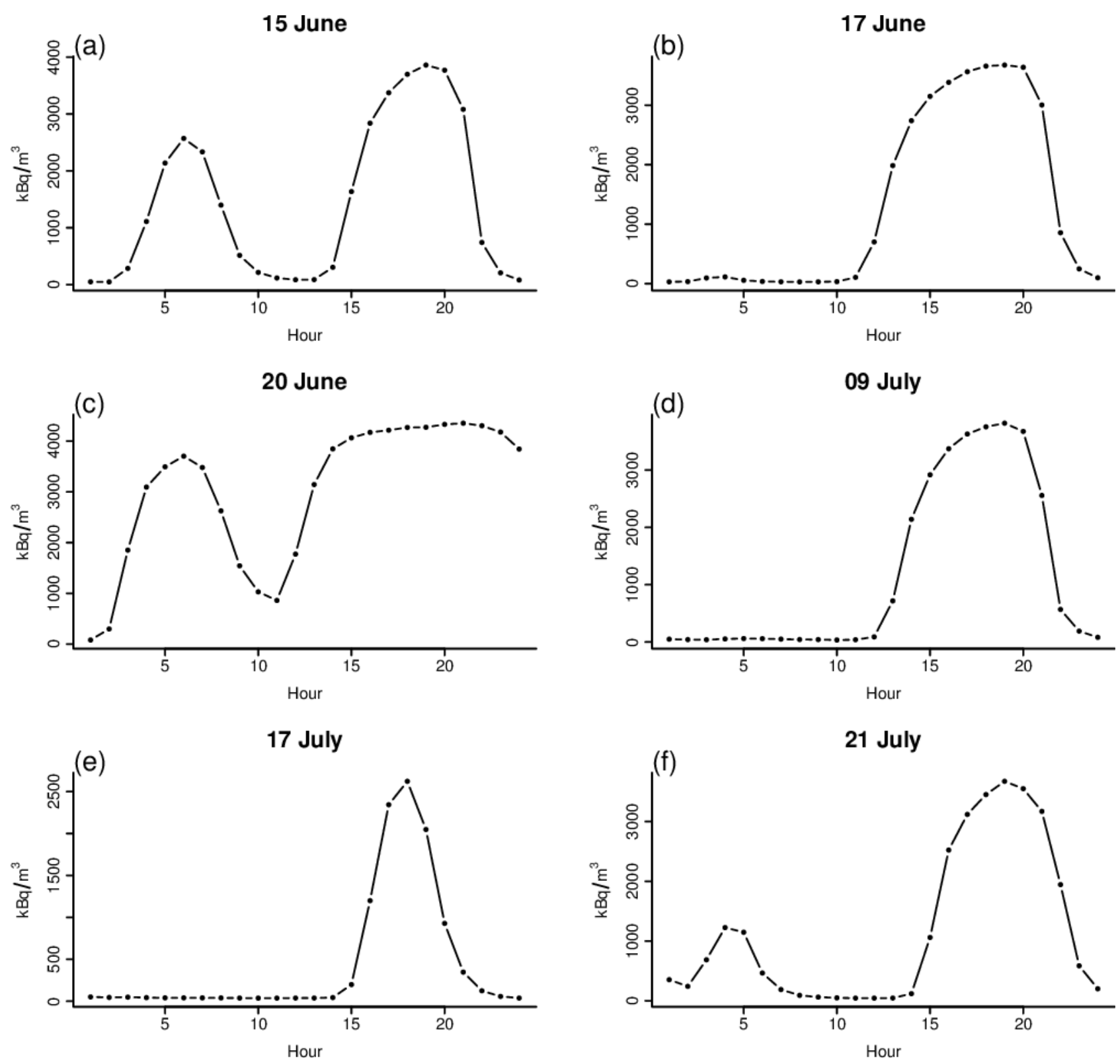
Figure 12: Hourly time series of radon concentration measured at $2.4 \mathrm{~m}$ for the whole year 2011. Gaps in May and August-September 2011 are due to instrumental issues.

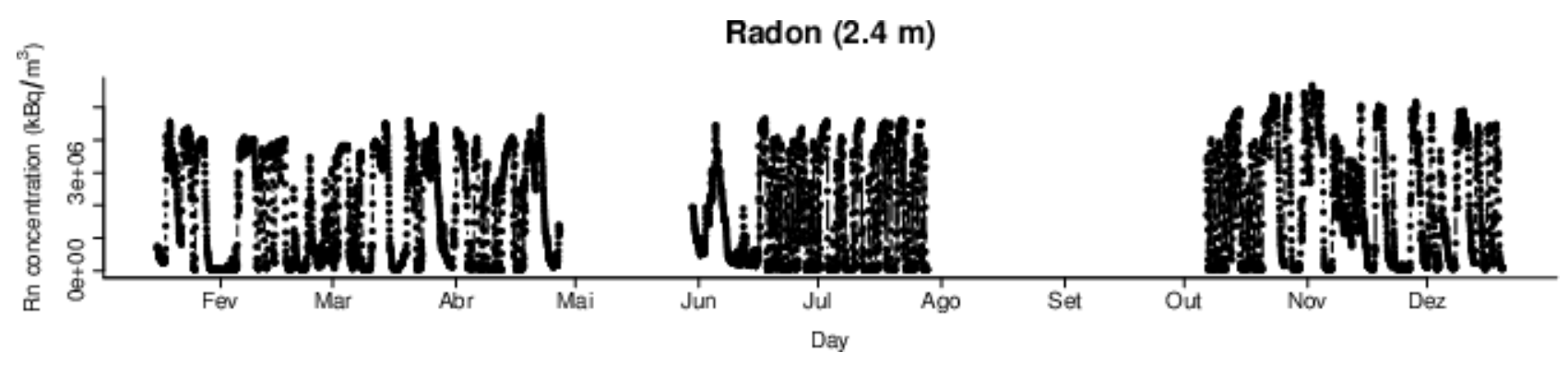

